

\title{
Participação social na organização da agenda e na gestão de políticas públicas de desenvolvimento rural ${ }^{*}$
}

\author{
Social participation in the organization \\ of the agrenda and in the management of \\ public policies for rural development
}

Caio Galvão de França

\begin{abstract}
Resumo
O artigo aborda a participação social como um dos principais elementos explicativos da criação de um conjunto de políticas públicas diferenciadas para a agricultura familiar e da organização de uma nova agenda do desenvolvimento rural no Brasil. A institucionalização de tais políticas revela mudanças no papel e na dinâmica da participação social associadas ao conteúdo das políticas públicas e de sua relação com as demandas dos movimentos sociais.
\end{abstract}

Palavras-chave: participação; desenvolvimento rural; políticas públicas.

\begin{abstract}
The paper discusses social participation as one of the main explanatory factors for the creation of a differentiated set of public policies for family farming and the organization of a new rural development agenda in Brazil. The institutionalization of these policies shows changes in the role and dynamics of social participation associated to the public policies content, as well as in the relation with the demands of social movements.
\end{abstract}

Key words: participation; rural development; public policies.

*Artigo elaborado a partir de apresentação no tema "Mobilizando atores para o diálogo sobre políticas agrícolas e agrárias: uma perspectiva a partir dos gestores de políticas públicas" do Seminário Internacional "Políticas públicas, atores e agricultura no Brasil: desafios e possibilidades em jogo", OPPA/CPDA-UFFRJ, realizado no Rio de Janeiro, nos dias 10 e 11 de novembro de 2011. 


\section{Introdução}

$\mathrm{N}$ os últimos anos observa-se no Brasil um processo de crescimento econômico com distribuição de renda, com acentuada redução da pobreza e da desigualdade. Essas reduções decorrem, em grande parte, de uma ampla rede de proteção e promoção social e de políticas públicas ativas de democratização econômica.

$\mathrm{Na}$ área rural, onde a redução da pobreza ocorre a uma taxa mais elevada, as transformações vinculam-se à constituição de um "complexo repertório de políticas e instrumentos de intervenção direcionados à agricultura, em especial, aos setores que historicamente não haviam sido contemplados por programas governamentais"1 - a agricultura familiar e as comunidades rurais. Ocorre a incorporação econômica e social de setores que estavam à margem e que passaram a disputar o sentido da ação estatal, o acesso a direitos, aos recursos públicos, e a própria orientação do desenvolvimento rural.

Um dado revelador da contribuição das políticas públicas de apoio à produção e de garantia de direitos à redução da pobreza está no significativo crescimento da participação da renda do trabalho na renda das famílias rurais. Ao processar, de forma original, os dados da Pesquisa Nacional por Amostra de Domicílios (Pnad), Del Grossi (2009) observa que, entre 2002 e 2008, "os aumentos das rendas do trabalho agrícola e não agrícola contribuíram em $56 \%$ do aumento da renda da agricultura familiar".

Há um conjunto de dados empíricos que ilustra a dimensão da ampliação do acesso desses segmentos às políticas públicas que impactam diretamente a capacidade produtiva, a geração de renda e de postos de trabalho. São programas preexistentes, cuja cobertura foi ampliada enormemente, e novos programas, abarcando todas as etapas do ciclo produtivo e novas dimensões do trabalho.

A democratização do acesso ao crédito rural subsidiado (Programa de Fortalecimento da Agricultura Familiar - Pronaf) e sua nacionalização contaram com a inclusão do financiamento de novas atividades produtivas e o aumento expressivo de recursos disponibilizados e de contratos (passaram de $R \$ 2,4$ bilhões, na safra 2002/2003, para R\$ 16 bilhões, na safra 2010/2011, e de 900 mil contratos para aproximadamente 1,5 milhão nos mesmos períodos). A garantia da renda passou a contar com novos instrumentos de seguro climático e de preços. No caso de intempéries climáticas, o Seguro da Agricultura Familiar (Seaf) garante o pagamento do valor financiado, além de garantir parte da renda de cerca de 500 mil agricultores e agricultoras. O seguro específico para a região semi-árida do Nordeste, o Garantia Safra, garante em 2011 a renda de 737 mil agricultores familiares em 990 municípios de 10 estados no caso de perda da produção. No caso de queda de preços dos produtos na hora da comercialização, o seguro de preços - Programa de Garantia de Preços para a Agricultura Familiar (PGPAF) - garante um desconto do valor financiado dos contratos do Pronaf. Constituiu-se um amplo mercado institucional para a produção da agricultura familiar com o Programa de Aquisição de Alimentos (PAA) e o Programa 
Nacional de Alimentação Escolar (PNAE), que beneficiam mais 203 mil agricultores e agricultoras em 2011. (MDA-2011)

Além de contemplar a agricultura familiar e as comunidades rurais, segmentos tradicionalmente políticos, as novas políticas ampliaram a presença desses segmentos na arena institucional e a participação deles na vida econômica e social. Há sinais de fortalecimento de sua capacidade de vocalização de interesses e de participação ativa em diferentes âmbitos. Suas demandas ganharam mais visibilidade e reconhecimento, traduzindo-se em políticas públicas que abrem novas possibilidades de organização econômica e que as conectam com temas centrais da agenda nacional, como o controle da inflação, a inclusão produtiva, a segurança alimentar, a promoção da igualdade das mulheres, a produção sustentável e o desenvolvimento regional. Passam a intervir mais diretamente sobre novas frentes, como a política internacional, em particular sobre a redefinição das regras do comércio internacional, a integração regional e a cooperação internacional.

Um dos principais elementos explicativos desse cenário de mudanças no país, e em particular na agenda do desenvolvimento rural, e da própria nova situação da agricultura familiar é a participação social desses segmentos. Partindo dessa compreensão, a análise das mudanças recentes na ação estatal dirigida ao desenvolvimento rural não pode deixar de discutir as alterações nos mecanismos e processos de participação social e seu rebatimento na organização da agenda e das ações, e na própria dinâmica de articulação dos diferentes atores.

A abordagem do tema está restrita, nos limites deste artigo, a um olhar sobre o âmbito nacional da articulação de atores sociais voltada a incidir sobre as políticas públicas de desenvolvimento rural, centrada nos aspectos que envolvem a interlocução de um setor específico do governo federal, o Ministério do Desenvolvimento Agrário (MDA), com entidades sindicais e movimentos sociais rurais, privilegiando alguns espaços e temas. O local de observação do autor foi sua experiência no período de 2003 a 2010 como coordenador do Núcleo de Estudos e Desenvolvimento Agrário e, depois, como Chefe de Gabinete do Ministro do MDA. Trata-se de um recorte analítico, pois a interlocução do governo federal com esses setores envolve outros órgãos federais.

O recorte adotado não prevê a análise de processos específicos de formulação e implantação de políticas públicas diferenciadas, nem a avaliação de seus resultados e de suas perspectivas. Não prevê a análise sobre a participação social que ocorre em outras esferas importantes, como a que se dá no Conselho Nacional de Desenvolvimento Rural Sustentável (Condraf), nos Conselhos Municipais, nos territórios rurais de identidade ou nas Conferências de Segurança Alimentar e Nutricional. Não prevê, também, a problematização dos aspectos referentes à autonomia dos movimentos frente às decisões governamentais e às transferências de recursos, apesar de relevantes para a discussão da dinâmica da participação social. 


\section{Preliminares sobre participação e novas políticas}

O marco de referência aqui adotado reconhece os avanços expressivos alcançados pelo Brasil no escopo das políticas públicas de garantia de direitos e de promoção da autonomia da agricultura familiar e das comunidades rurais tradicionais. Avanços que convivem e conflitam com limites políticos e institucionais, que precisam ser superados para que a agenda do desenvolvimento rural se consolide e ganhe mais relevância na nova dinâmica do desenvolvimento nacional.

O cenário decorrente de mudanças econômicas, políticas e institucionais alterou as condições objetivas de vida da base social dos principais movimentos rurais, reconfigurou as contradições e redefiniu as condições de formulação e implementação de políticas públicas e da própria disputa de projetos. Tais mudanças repercutem sobre as expressões contemporâneas da questão agrária e dão novos contornos ao esforço para que ela seja tratada como elemento importante do aprofundamento da democracia e de um projeto nacional.

O crescimento da participação política, para além de sua importância para a nova agenda do desenvolvimento rural, é uma das dimensões da própria trajetória democratizante do Brasil. Com essa compreensão Avritzer (2011) assinala que ela se expande do local para o nacional, forma uma vasta institucionalidade, "segmentada em um conjunto bastante grande de instituições", e revela "a presença de formas ampliadas de participação na democracia brasileira". Uma participação que expressa a energia da ação coletiva de atores populares, e que resulta em fortalecimento dos movimentos sociais e suas lutas e em reconhecimento da legitimidade de suas demandas e projetos, bem como na criação de políticas. Uma participação que desdobra a dimensão da autonomia, da representação política e da participação institucional, e que afirma uma pluralidade política fundamental para a própria democratização do país. Uma participação associada ao processo de construção e afirmação de novos atores sociais, que se vincula ao debate intelectual de crítica da modernização conservadora da agricultura e ao questionamento de padrões de análise sobre o rural brasileiro, que remonta ao período anterior à redemocratização.

É essa percepção sobre o significado da crescente participação política que fundamenta a existência de um feixe de políticas públicas diferenciadas aplicadas ao meio rural. São políticas agrícolas, agrárias e de promoção da igualdade das mulheres rurais, que compõem o que poderia ser chamado de uma agenda democrática do desenvolvimento rural.

A participação na produção de políticas de desenvolvimento rural tem múltiplas características. Ela ocorre em espaços formais institucionalizados, em espaços informais de interlocução, regulares ou eventuais, e passa, também, pela energia das mobilizações e das lutas de um conjunto diverso de atores sociais. Essa participação atua sobre a deliberação das políticas de maneira ampla, em disputas abertas na sociedade, na pressão social articulada à apresentação e discussão de propostas em 
espaços institucionais. Atua sobre um amplo leque de temas da agenda nacional e sobre aqueles relacionados mais diretamente ao desenvolvimento rural e, mais recentemente, em espaços internacionais, articulada em redes e fóruns mais amplos.

A expressão "participação", com toda a sua multidimensionalidade, é aqui utilizada como categoria prática "mobilizada para conferir sentido à ação coletiva de atores populares", carregada de uma "visão emancipatória" desses setores, impregnada dos valores da autodeterminação e da inclusão (LAVALLE, 2011). O foco dirige-se à articulação de atores para incidir sobre políticas públicas de desenvolvimento rural.

Outra referência adotada é o reconhecimento de que as novas políticas produzem efeitos de curto e longo prazos sobre os atores sociais, assim como nas políticas públicas e no próprio debate intelectual. Ao analisar os efeitos políticos das novas políticas criadas sobre os próprios atores sociais que agiram para que elas fossem constituídas, Santos (2011) destaca "o de fortalecer a coalizão em defesa da agricultura familiar e de consolidar a disputa desta com a agricultura patronal como elemento central das definições de política agrícola no Brasil ao longo dos últimos 15 anos".

Partindo dessa compreensão geral, o primeiro registro a ser feito é o de que há, nesse período, uma mudança no papel e na dinâmica da participação social na configuração da agenda e das políticas públicas de desenvolvimento rural. Para tratar dessa mudança adota-se uma periodização da trajetória, ainda recente, de institucionalização dessas políticas em três momentos, com ênfase no seu conteúdo e na relação com as demandas dos movimentos.

O recurso metodológico de estabelecer uma periodização e destacar as mudanças na participação social na institucionalização das políticas públicas não se sobrepõe à compreensão de que há uma continuidade importante na pressão social sobre o governo e sobre o Estado. Em todos os momentos dessa trajetória mantevese, de forma renovada e variada, uma pressão, necessária e legítima, nos espaços institucionalizados, nos processos permanentes de interlocução e nas lutas sociais, dirigida à ampliação e qualificação das políticas públicas e seus instrumentos e para que a agricultura familiar e a reforma agrária fossem mais valorizadas na nova dinâmica do desenvolvimento nacional. Os conflitos e as divergências públicas e o tom mais crítico dos discursos políticos e das plataformas nas mobilizações não resultaram em interrupção da participação social nas políticas públicas e na interlocução em seus vários níveis. Há, portanto, uma estreita relação entre a evolução da participação, da institucionalização das políticas e a das mobilizações sociais.

\section{Momento de afirmação social}

Em um primeiro momento dessa periodização a participação dirigiu-se, prioritariamente, para desvelar a diversidade da agricultura e do meio rural, para afirmar uma pauta de reivindicações e a legitimidade dos atores que as apresentam e para alimentar a resistência aos efeitos da modernização conservadora da agricultura 
e a própria luta pela redemocratização do país. Uma participação voltada para a afirmação da identidade social e das demandas da agricultura familiar, da diversidade das populações rurais e de novas possibilidades de desenvolvimento, em contraposição a uma longa história de exclusividade dos grandes proprietários de terra e grandes produtores rurais como únicos porta-vozes do rural. E, como indicado anteriormente, trata-se de uma participação vinculada à elaboração intelectual de crítica ao padrão de desenvolvimento da agricultura, de análise da diferenciação social da agricultura brasileira, sobre a importância da reforma agrária e a memória das lutas camponesas.

Num cenário de exclusão e de ausência de políticas públicas, além da retomada das mobilizações e das lutas, surgiram experiências associativas com variadas ações dirigidas às populações rurais. São experiências alternativas de organização econômica, no plano da produção e da comercialização, de educação popular, de assistência técnica, em geral articuladas às lutas para garantir o direito à terra.

Para efeitos de sua localização no tempo, esse primeiro momento da participação social na trajetória de institucionalização das políticas remonta à redemocratização e chega a 2002. Nesse período destacam-se algumas mudanças importantes. Criou-se o Pronaf, o Ministério do Desenvolvimento Agrário, o Conselho Nacional de Segurança Alimentar e o Conselho Nacional de Desenvolvimento Rural Sustentável, e retomouse, com intensidade, a política de assentamentos rurais. Reconheceu-se o direito dos trabalhadores rurais em regime de economia familiar à previdência social na Constituição Federal de 1988, e a efetivação de acesso a partir da regulamentação de 1991, uma demanda histórica dos movimentos sociais e tradicionalmente presente nas suas pautas. No período prevaleceu um padrão de oposição política dos movimentos sociais rurais com o governo federal, que conviveu com processos negociais em torno de algumas demandas, e o apoio público para a implementação de projetos de entidades da sociedade civil.

\section{Reivindicação institui agenda e se institucionaliza}

Identifica-se um segundo momento na trajetória da participação social na institucionalização das políticas públicas de desenvolvimento rural com a vitória eleitoral de Lula nas eleições presidenciais e o início de seu primeiro mandato em 2003. Essa mudança de governo transformou o contexto da participação social e impactou a evolução das políticas diferenciadas para a agricultura familiar.

A mudança de governo levou ao reconhecimento da pluralidade política e social da agricultura e ampliou e valorizou a participação social, que produziu - e se traduziu em - uma transformação qualitativa e quantitativa das políticas públicas de desenvolvimento rural. Um processo de ampliação, reformulação e criação de políticas, de estabelecimento de novos vínculos das políticas com a agenda nacional e com a agenda de decisão do governo federal. A natureza e a dimensão da mudança produziram uma inflexão na trajetória anterior de tais políticas. 
O apoio dos movimentos ao candidato Lula na disputa eleitoral polarizada produziu grandes expectativas em relação ao novo governo e expressou identidade com aspectos importantes de seu programa. Nesse ambiente processou-se uma convergência conflitiva das reivindicações dos movimentos em direção à agenda de um governo que as reconhecia e as assumia. Reivindicações históricas, novas demandas e experiências inovadoras locais foram incorporadas pelo Estado, institucionalizadas como políticas públicas. Passo a passo, mobilização a mobilização, negociação a negociação, ano a ano, políticas foram sendo retomadas em novas bases, novas políticas foram criadas, novos temas incorporados.

A importância das políticas diferenciadas e de seu alcance reside no fato de que elas potencializam o protagonismo econômico da agricultura familiar e das comunidades rurais tradicionais; requalificam sua inserção econômica local e regional; incidem para superar a desigualdade imposta às mulheres rurais e promover sua autonomia econômica; impactam o ordenamento territorial. São políticas de garantia do direito à terra e de democratização da estrutura fundiária, de apoio à produção e garantia da renda - crédito, comercialização, agroindustrialização, energia elétrica, seguro de preços e climático -, de acesso ao conhecimento e à educação - assistência técnica, educação do campo -, de desenvolvimento territorial, de segurança alimentar e nutricional e de integração regional (FRANÇA; SORIANO, 2010).

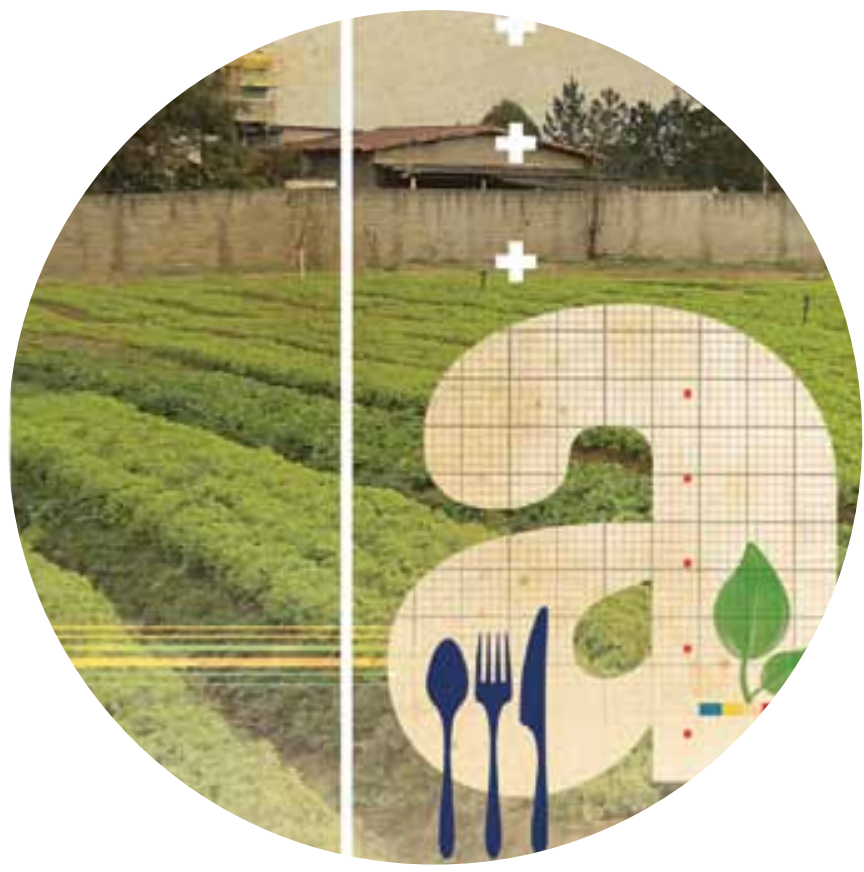


A participação social atuou na promoção de inovações relevantes e nos principais temas que marcaram esse período. Uma das inovações foi a instituição do Plano Safra da Agricultura Familiar, a partir de 2003 como momento anual de atualização das regras e dos procedimentos das políticas e anúncio de novos instrumentos, antecedido por negociações com os principais movimentos e internas ao governo federal, com pautas e discussões públicas acompanhadas de mobilizações. Outra inovação foi a aprovação da LEI 11.236, 24/7/2006 a chamada Lei da Agricultura Familiar, um marco do reconhecimento institucional desse segmento da agricultura e das políticas públicas diferenciadas.

A participação social está na origem do processo de entrada na agenda do governo do II Plano Nacional de Reforma Agrária (II PNRA) e no processo de sua elaboração. Mesmo antes do seu anúncio, a atuação dos movimentos rurais foi decisiva para atribuir centralidade à fixação das metas de famílias a serem assentadas, o que acabou limitando a avaliação da execução do Plano e restringindo o debate público nacional sobre a reforma agrária.

A participação foi fundamental para o processo de fortalecimento institucional do MDA e do Incra, com a ampliação de suas atribuições, de seu orçamento e das políticas sob sua coordenação na agenda governamental. A mesma importância observa-se na retomada do Consea e em toda a sua atuação dirigida à afirmação da segurança alimentar, sua institucionalização no marco legal e como política nacional, desdobrada em vários instrumentos para sua operacionalização por diferentes órgãos de governo.

A ideia central é de que nesse período a pauta histórica reclamada pelos movimentos sociais e impulsionada pela participação social realizou-se como principal elemento instituinte do estabelecimento da agenda de decisão do governo federal e das políticas públicas para a agricultura familiar.

$\mathrm{E}$, a partir daí, gradualmente, mas não linearmente, as pautas de reivindicações dos movimentos deslocaram-se, não completamente, da demanda pela criação de políticas e novos instrumentos para a promoção de ajustes incrementais nas políticas, nas suas condições e em seus procedimentos (por exemplo, ampliação do volume de recursos destinados e do público beneficiado, melhorias das condições financeiras etc.).

Observa-se, também, a intensificação da demanda pela ampliação da participação dos movimentos e das organizações na execução das políticas públicas de desenvolvimento rural. Vale registrar que não se trata de um tema novo, pois várias das políticas solicitadas socialmente e constituídas desde o processo de redemocratização - em diferentes áreas - previam atribuições às entidades da sociedade civil, entre elas e em alguns casos, a participação na execução da própria política pública. 


\section{Ação instituinte governamental}

O marcador do terceiro momento da trajetória da participação social na institucionalização das políticas públicas de desenvolvimento rural é o início do segundo mandato do presidente Lula, em 2007. Aqui não é propriamente a mudança de governo, mas a mudança na agenda do governo, que repercute sobre a dinâmica da participação social, e o processo de formulação das políticas, que marcavam a experiência do MDA até então.

A ideia central é de que a ação instituinte, em alguns temas muito importantes, desloca-se da participação social para a esfera governamental. As novas políticas e programas desse período são, de forma geral, geradas internamente às instâncias de governo, no âmbito mais estrito do MDA e de suas mediações interministeriais, e, posteriormente, transferidas para a arena pública e objeto da interlocução social. Essas características foram identificadas, por exemplo, na análise da formulação do programa Territórios da Cidadania e sua entrada na agenda do governo federal, como analisado por França (2009), no programa Terra Legal e no programa Mais Alimentos. ${ }^{2}$ Não se trata, aqui, de analisar os processos de formulação de cada um deles, claramente distintos. Mesmo reconhecendo a existência de importantes diferenças, é possível destacar alguns aspectos comuns que permitem incluí-los nesse registro.

Essas iniciativas não emergem diretamente das pautas de reivindicações e não expressam diretamente demandas institucionalizadas e propostas mais consolidadas dos movimentos, como no período anterior. Apesar de existirem registros que permitem identificar alguma relação com temas presentes nas agendas e plataformas dos movimentos sociais. Além disso, as condições para a formulação e legitimação interna no governo das novas iniciativas não decorreram de mobilizações específicas e nesse processo não se observou o mesmo padrão de interlocução do MDA com os movimentos sociais sobre as políticas públicas.

Essas iniciativas foram possíveis, especialmente, pela combinação: i) do acúmulo político institucional anterior, expresso pelo fortalecimento do MDA e da agenda do desenvolvimento rural e pela preexistência de um conjunto de políticas públicas, mesmo que com um grau diferenciado de abrangência e consolidação, que demandavam e, ao mesmo tempo, possibilitavam avançar na coordenação e integração de ações, em âmbito federativo, intersetorial e intragovernamental (uma prioridade assumida e anunciada pelo MDA para o novo mandato); ii) com “janelas de oportunidade" na agenda de decisões do governo, seja em função da prioridade dada pela nova "Agenda Social" no combate à pobreza rural, seja em função da visibilidade e da relevância dos temas que envolvem a Amazônia, seja em função dos efeitos da crise internacional sobre os preços dos alimentos e dos avanços no tema da segurança alimentar e nutricional; iii) e a existência, mesmo que não acionada, de uma força e um acúmulo político e organizativo dos movimentos sociais rurais. 
São programas e políticas que contêm redes mais complexas de implementaçãoe de governança, com ênfase em elementos de coordenação federativa e intersetorialidade, e são voltadas a temas mais amplos que o escopo dos instrumentos anteriormente criados. Programas de outra natureza, o que leva a que alguns considerem que se trata de uma segunda geração de políticas públicas para o meio rural.

Há diferentes possibilidades explicativas para a mudança observada na participação social na definição da agenda e da formulação desses novos programas, para esse descompasso entre a atuação dos movimentos e do governo federal. Podese considerar que isso se deu pelo fato de se tratar de um período de transição nas próprias agendas e pautas dos movimentos sociais impactados pelo recém-criado "complexo repertório de políticas e instrumentos de intervenção direcionados à agricultura" (UFRRJ-2011), em um cenário de transformações nas condições objetivas de reprodução de parte da classe trabalhadora no campo, de novas dificuldades associadas à participação na execução das políticas públicas e de conflitos políticos decorrentes de contradições e ambiguidades da própria agenda do governo federal. Ou, ainda, de que essa mudança poderia estar associada ao crescimento da participação, que significou a ampliação do leque de temas e de instâncias em diferentes esferas - local, regional, nacional, internacional -, que tensionam a dinâmica da articulação dos atores sociais e exigem deles esforços nada simples de coordenação. Não se deve desconsiderar, também, que possíveis divergências políticas ou críticas ao governo e ao processo de formulação possam ter influído na atitude dos movimentos em relação a tais programas. No entanto, elas não devem ser sobrevalorizadas, pois tais iniciativas não estão em contradição com as plataformas dos movimentos, e o descompasso não gerou crises. $^{3}$

A explicação pode estar associada a um estranhamento por parte dos movimentos em relação a essas novas ações públicas, em função de a experiência anterior de participação - na interlocução com o governo federal sobre políticas públicas - ter se concentrado na formulação e no acompanhamento da gestão de políticas e instrumentos setoriais específicos, como crédito, seguro etc. A nova agenda trouxe dificuldades também para os gestores, mas a responsabilidade institucional para resolver problemas de integração e coordenação de políticas e a necessidade de aproveitar as oportunidades que surgiram obrigou-os a responder rapidamente.

Esse estranhamento poderia estar relacionado com as próprias características dos temas e a forma como eram tratados pelos movimentos. É evidente que a luta pela superação da pobreza rural, pela garantia do direito à terra na Amazônia e por avanços na inserção econômica estavam e estão presentes nos discursos do sindicalismo rural e dos movimentos sociais. $\mathrm{O}$ aspecto a destacar é que nesses temas, diferentemente de outros, a presença no discurso dos movimentos não se desdobrou em bandeiras e reivindicações mais claras ou em pressões mais focadas sobre a agenda do governo. Mesmo a experiência anterior na política de desenvolvimento territorial, apesar dos elementos de articulação federativa, de ações em rede e de intersetorialidade presentes 
na abordagem territorial, não produziu uma demanda organizada e institucionalizada para que os movimentos sociais pautassem ou priorizassem a discussão de novos programas e políticas com tais características.

Pode-se, ainda, especular outra via explicativa. A trajetória da participação social e da interlocução dos movimentos com o MDA, e com o governo federal, produziu um ambiente de confiança e de cumplicidade que permitia que a formulação dos novos programas percorresse um caminho próprio, mais restrito ao âmbito do governo, sem que isso fosse interpretado como uma ruptura no padrão de diálogo social constituído. Mantinha-se a confiança de que os espaços de participação nos novos programas estariam garantidos e que sua criação se originava de preocupações comuns. A experiência recente de produção de políticas que fortaleceram econômica e socialmente os movimentos e a vigência de um espaço efetivo para a promoção das mudanças incrementais consistiriam num certificado de garantia.

O mútuo reconhecimento produzido nessa trajetória compartilhada informava a noção de que movimentos, entidades da sociedade civil, MDA e outros órgãos federais compunham um mesmo campo político - "a turma do rural" -, que atuava, cada um a seu modo, para sustentar uma agenda comum na política agrária, na segurança alimentar e nutricional, nas políticas para as mulheres, no desenvolvimento territorial, na produção sustentável. Essa noção ficou evidente na I Conferência Nacional de Desenvolvimento do Brasil Rural Sustentável e Solidário (2008), que, para além das diferenças e divergências naturais, expressou nas discussões e em suas deliberações um leque de preocupações e referências comuns, tanto sobre o acúmulo institucional conquistado, como sobre o "Brasil Rural que queremos".

Outro aspecto da participação nas políticas de desenvolvimento rural a ser assinalado refere-se à ampliação do peso da ação governamental, seja na convocação à participação ou no estímulo à articulação dos atores à participação, seja na organização da agenda de temas específicos importantes. Em algumas situações, esse tipo de iniciativa governamental decorre do interesse em ampliar a pluralidade e fortalecer os espaços institucionais, e, assim, garantir a própria efetividade da ação pública. Em outras situações, a iniciativa governamental decorria da constatação da ausência de articulação prévia e específica dos movimentos sobre um dado tema, de articulação preexistente parcial e incompleta ou cuja configuração era demarcada por divergências entre os movimentos. Havia, ainda, situações em que o tema a ser tratado ainda não tinha sido objeto de reflexão consolidada pelos movimentos ou existiam percepções muito diferenciadas entre eles. Casos ilustrativos são o da participação nas negociações internacionais da Rodada Doha da Organização Mundial do Comércio (OMC); o processo de criação e animação da Reunião Especializada da Agricultura Familiar do Mercosul (Reaf), e, até mesmo, o da participação das mulheres rurais nos seus fóruns"; a preparação da participação brasileira na Conferência Internacional de Reforma Agrária e Desenvolvimento Rural da Organização das Nações Unidas para a Agricultura e Alimentação (FAO), realizada no Brasil em 2006, e nas principais instâncias 
desse organismo internacional. Nesses espaços, mesmo que de forma diferenciada, também se observou a expressão de um campo político comum formado pelo MDA (e outros atores governamentais) e os movimentos sociais rurais. Em todos esses momentos a participação social produziu efeitos benéficos para os movimentos e para a atuação governamental setorial. Os movimentos ampliaram e aprofundaram o escopo de sua atuação, ampliaram sua interlocução regional e internacional, produzindo um "tecido social organizado" que fortalecia a ação governamental e propiciava avanços nesses fóruns. É como se as posições e as iniciativas do governo fossem uma referência séria para a ampliação da articulação internacional dos movimentos, fortalecendo sua capacidade de influenciar, e, ao mesmo tempo, essa articulação produzisse condições mais favoráveis para a própria atuação do governo nesses fóruns. Como se cada um, a cada momento, contasse com o outro, como um tipo de retaguarda.

\section{A dimensão da militância e da experiência prévia}

Há um outro aspecto nem sempre devidamente considerado para a compreensão da nova dinâmica da participação social e das políticas diferenciadas. Trata-se da história e trajetória dos militantes que passaram a exercer a direção central e setorial do MDA, mais um elemento que compõe o ambiente da mudança no governo federal.

Antes de assumir esses postos institucionais, eles e elas estavam ou tinham estado em experiências de governo de esquerda que impulsionaram formas de democracia participativa e políticas de democratização econômica; estavam na assessoria de movimentos sociais e em organizações não governamentais, desenvolvendo experiências alternativas e participando das mobilizações e das lutas sociais. Muitos militavam no Partido dos Trabalhadores, onde participaram da formulação de políticas agrárias e agrícolas e, inclusive, do programa Fome Zero. Alguns integraram o núcleo de direção de uma administração pública estadual, experiência útil para orientar a atuação no interior do governo federal, e especialmente na relação com o núcleo central, a partir de um órgão setorial. Esses militantes compartilhavam um compromisso político de valorização da reforma agrária e da agricultura familiar, não apenas pela dimensão da justiça social, mas também pela sua importância econômica para promover e sustentar o crescimento, para fortalecer o mercado interno de massas, para garantir a produção de alimentos e para dinamizar as regiões rurais. Posições e experiências que, associadas às de militantes que atuavam em outros órgãos, ajudaram a superar resistências e a ganhar o apoio de setores importantes do governo federal para as novas políticas públicas.

Vale registrar que processos semelhantes, com suas especificidades, ocorreram em outros ministérios e órgãos setoriais importantes para o desenvolvimento rural como Ministério do Desenvolvimento Social e Combate à Fome, Companhia Nacional de Abastecimento - Conab. 
Portanto, a combinação de uma trajetória anterior de compromisso com as reivindicações e os movimentos sociais, com a constituição de uma equipe com experiências anteriores na área e de gestão pública repercutiu sobre a dinâmica da participação social e influenciou a incorporação de novos atores e de novas políticas na agenda do governo federal.

\section{Para além da unidade política dos movimentos}

Há outro registro a ser feito no que se refere à articulação dos atores para a participação social. Refiro-me às dificuldades existentes para a constituição de um processo comum, unificado e plural, de interlocução dos movimentos sociais rurais com o MDA e com o governo federal, compatível com a preservação da autonomia dos movimentos e da "concorrência" entre eles pela representação dos diversos setores que compõem o amplo universo da agricultura familiar e das comunidades rurais.

Deve-se reconhecer e valorizar o fato de haver uma rica história de organização de marchas, campanhas, jornadas e lutas que se impõem como momentos particulares da interlocução de cada movimento com o governo federal. Ações coletivas que ganharam mais visibilidade social e que produziram diversas conquistas traduzidas no reconhecimento e na efetivação de direitos e na ampliação de sua participação econômica. O "Grito da Terra", a "Jornada da Agricultura Familiar", a "Marcha das Margaridas", as jornadas de mobilização dos movimentos de luta pela terra e as mobilizações dos quilombolas e dos trabalhadores extrativistas são momentos de afirmação da identidade de cada organização, de educação política das direções e suas bases, de visibilidade pública e de divulgação de suas reivindicações e de suas conquistas.

Essas ações expressam a heterogeneidade social e as trajetórias próprias de afirmação de identidades e de demandas específicas dos setores populares do meio rural e são fundamentais. São as bandeiras e reivindicações de cada segmento social que impulsionam a participação de suas entidades representativas e constituem referências necessárias para a avaliação de conquistas e para a própria legitimação dos movimentos perante suas bases sociais. Informam, também, as iniciativas de articulação com outras entidades e movimentos e a construção de pautas comuns. As mobilizações produzem efeitos sobre o processo de negociação intragovernamental e favorecem as posições do MDA nas disputas internas ao governo. Contribuem para superar limitações conjunturais nos processos de formulação e de implementação e para ampliar e abrir novos espaços institucionais, no interior do governo federal, para as políticas públicas diferenciadas. Um indicador econômico da funcionalidade das mobilizações é o crescimento do orçamento setorial e, em particular, dos investimentos.

No ambiente de interlocução regular e permanente do MDA, e do governo federal, com os movimentos sociais, as mobilizações individualizadas, entretanto, complexificam o diálogo social sobre as políticas públicas - e não apenas sobre as 
A construção de coalizões sociais mais amplas e a afirmação dessa agenda de caráter estratégico são dimensões do mesmo processo, no qual um projeto com vocação hegemônica submete-se, democraticamente, à escolha social.

Num cenário de continuidade de crescimento econômico com distribuição de renda, redução da pobreza e das desigualdades, e avanço das políticas sociais com suas potencialidades para garantir acesso universal aos direitos fundamentais, será preciso combinar, pelo menos, duas dimensões na dinâmica da participação social e da articulação dos atores. Por um lado, produzir a força social necessária para efetivar os direitos, com as especificidades adequadas a cada segmento social e considerando as múltiplas possibilidades de acesso. Por outro lado, redesenhar novas demandas e criar as melhores condições para sua afirmação como parte de uma agenda dirigida a aprofundar a democracia econômica e política.

\section{Considerações ao final}

Os registros apresentados pretenderam ilustrar a assertiva de que o novo cenário formado pelo recém-criado "complexo repertório de políticas e instrumentos de intervenção direcionados à agricultura"( UFRRJ 20111) e por novos programas repercute sobre o papel e a dinâmica da participação social na configuração da agenda e das políticas públicas de desenvolvimento rural. A participação social, com suas demandas específicas e as mobilizações que as impulsionam, permitiu o desenvolvimento das políticas públicas e o desenvolvimento dessas políticas contribuiu para uma maior participação. Novas demandas atendidas produzem mais apoio para as políticas e abrem possibilidades para novas conquistas.

A interlocução direta das direções dos movimentos com o governo federal e as direções dos ministérios não é uma novidade, mas se evidenciam mudanças importantes. Mais organizações passaram a ter acesso ao núcleo de decisão do governo, incluindo novas organizações sindicais e entidades representativas de setores antes excluídos da interlocução, como extrativistas, pescadores e quilombolas. $\mathrm{E}$ os resultados da interlocução são muito concretos como expressam as diversas políticas diferenciadas criadas.

Os avanços combinados nas políticas de proteção social, segurança alimentar e nutricional e de apoio à agricultura familiar já mostram seus resultados no combate à pobreza e na sustentação do próprio crescimento. As mudanças institucionais e de orientação do governo federal favoreceram o protagonismo político dos novos atores, reconfiguraram as arenas políticas, as condições de tratamento dos conflitos e a própria expressão das contradições entre os setores da agricultura e seus diferentes projetos. $\mathrm{E}$, talvez pudesse ser acrescido, redesenharam a agenda democrática do desenvolvimento rural.

Trata-se de uma trajetória de institucionalização de políticas públicas, recente e heterogênea, mas que já se tornou referência internacional, que deverá percorrer 
alguns passos antes da sua constituição como um sistema nacional e completo, com a flexibilidade necessária para permitir as inovações na contraordem.

A compreensão de que a sociedade civil é precondição para uma participação exitosa e de que os conflitos e as lutas sociais fazem parte do próprio processo de formulação e implementação das políticas públicas de desenvolvimento rural implica, também, desafios metodológicos e políticos na análise da efetividade dessa participação social. Demanda um olhar sobre os momentos deliberativos e os não deliberativos, sobre os contextos particulares, sobre os desenhos institucionais (para além de suas competências deliberativas), sobre os resultados das políticas ao longo do tempo, em especial seus resultados distributivos ${ }^{6}$, sobre a relação da dinâmica própria de cada movimento e as questões que envolvem a articulação dos atores e, ainda, sobre o lugar da participação na própria agenda de governo.

A experiência concreta de participação é fundamental para o sucesso das políticas públicas, importante para sua harmonização e para sua sustentação na agenda do governo, para a conquista de novos espaços intragovernamentais, para afirmação de novas possibilidades e referências para o desenvolvimento rural e, especialmente, para o próprio avanço da democracia participativa. Já contamos com uma agenda reconhecida e institucionalizada. Contamos com um conjunto amplo de instrumentos (abrangentes, mas ainda não universais), teoricamente articulado para abarcar as várias dimensões da produção e da reprodução social da agricultura familiar e das comunidades rurais, que já mostrou seu efeito sobre a redução da pobreza, para a dinamização de regiões e para o fortalecimento econômico e social desses atores.

Contamos com movimentos sociais com uma vitalidade testada em diferentes períodos e um contexto institucional e governamental favorável, com suas próprias contradições, que permitem redefinir o próprio horizonte de possibilidades da participação social.

\section{Notas}

OPPA/CPDA-UFRRJ, Folder do Seminário "Políticas públicas, atores e agricultura no Brasil: desafios e possibilidades

2 Há aspectos dos programas e das políticas dirigidas à promoção da igualdade e da autonomia econômica das mulheres rurais que os aproximam do padrão discutido neste tópico, mas exigem uma reflexão específica em função das particularidades da interlocução intensa e qualificada entre o MDA e as organizações feministas e movimentos de mulheres (cf. BUTTO; HORA, 2008; BUTTO; DANTAS, 2011).

O caso do programa Terra Legal tem especificidades importantes, pois no processo de sua formulação e implementação produziu-se um ambiente mais explícito de divergências, influenciado pelas tensões na agenda ambiental e da reforma agrária.

4 Para uma análise de aspectos da participação das mulheres rurais e suas organizações na Reaf, ver Butto e Hora (2010).

Esses são alguns dos aspectos assinalados por Árabe, Moraes e Paula e Silva (2008) para a inserção da reforma agrária na agenda do desenvolvimento nacional, e por Guilherme Cassel, ex-ministro do Desenvolvimento Agrário, em dois artigos publicados na Folha de S. Paulo, intitulados "A atualidade da reforma agrária" (4/3/2007) e "Agricultura Familiar, escolhas e desafios" (30/7/2007).

6 Transposição de aspectos destacados por Avritzer (2011) ao discutir aspectos metodológicos da literatura sobre efetividade das instituições participativas. 


\section{Referências}

AVRITZER, L., 2011. A qualidade da democracia e a questão da efetividade da participação: mapeando o debate. In: PIRES, R. R. (Org.). Efetividade das instituições participativas no Brasil: estratégias de avaliação. Brasília: Ipea, 2011.

BUTTO, A.; HORA, K. E. R., (2008). Mulheres e reforma agrária no Brasil. In: BUTTO, A.; LOPES, A. (Org.). Mulheres na reforma agrária: a experiência recente no Brasil. Brasília: MDA, 2008. (Nead Debate, 14).

BUTTO, A.; HORA, K. E. R., 2010. Integração regional e políticas para as mulheres rurais no Mercosul. In: SCOTT, P.; CORDEIRO, R.; MENEZES, M. (Org.). Gênero e geração em contextos rurais. Ilha de Santa Catarina: Ed. Mulheres, 2010.

BUTTO, A.; DANTAS, I. (Org.), 2011. Autonomia e cidadania: políticas de organização produtiva para as mulheres no meio rural. Brasília: MDA. 2011.

DEL GROSSI, M. E., 2009. Assessment of social inclusion policy in rural areas: transformations through family allowance policy and public policy for family farming. Trabalho apresentado na International Conference 'Dynamics of Rural Transformation in Emerging Economies'. New Delhi, India, 2010.

FRANÇA, C. G., 2009.. Territórios da Cidadania e política de gestão pública. 2009. Trabalho de Conclusão de Curso (Especialização em Gestão Pública) - Ilape/Cepeg, 2009.

FRANÇA, C. G.; SORIANO, J., 2010. Territórios da Cidadania: inovação na trilha do Fome Zero. In: SILVA, J. F. G.; DEL GROSSI, M. E.; FRANÇA, C. G. (Org.). Fome Zero: a experiência brasileira. Brasília: MDA, 2010.

LAVALLE, A. G., 2011. Participação: valor, utilidade, efeitos e causa. In: PIRES, R. R. (Org.) Efetividade das instituições participativas no Brasil: estratégias de avaliação. Brasília: Ipea, 2011 MDA - Relatórios Internos,2011

SANTOS, F. P., 2011. Coalizões de interesses e a configuração política da agricultura familiar no Brasil. 2011. Tese (Doutorado em Administração Pública e Governo) - Escola de Administração de Empresas de São Paulo da Fundação Getúlio Vargas, São Paulo, 2011.

UFRRJ - OPPA/CPDA, FOLDER DO SEMINARIO INTERNACIONAL POLITICAS PÚBLICAS, ATORES E AGRICULTURA NO BRASIL: DESAFIOS E POSSIBILIDADES EM JOGO", 10 E 11 DE NOVEMBRO DE 2011, RIO DE JANEIRO

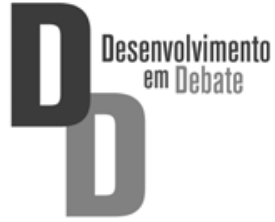

